\title{
Intravenous administration of L-tryptophan stimulates gastrointestinal hormones and melatonin secretions: study on beef cattle
}

\author{
Sang-Bum Lee ${ }^{1}$, Kyung-Won Lee ${ }^{2}$, Tao Wang ${ }^{3}$, Jae-Sung Lee ${ }^{1,4}$, U-Suk Jung ${ }^{1}$, Jalil Ghassemi Nejad ${ }^{1,4}$, \\ Young-Kyoon $\mathrm{Oh}^{5}$, Youl-Chang Baek ${ }^{5}$, Kyoung Hoon Kim ${ }^{6}$ and Hong-Gu Lee ${ }^{1,4^{*}}$ \\ 'Department of Animal Science and Technology, College of Animal Bioscience and Technology, Konkuk University, Seoul 05029, Korea \\ ${ }^{2}$ Life Science Technology, Inc., Seoul 06134, Korea \\ ${ }^{3}$ Department of Animal Nutrition and Feed Science, College of Animal Science and Technology, Jilin Agricultural University, Jilin 130118, China \\ ${ }^{4}$ An Educational Program for Specialists in Global Animal Science, Brain Korea 21 Plus Project, Konkuk University, Seoul 05029, Korea \\ ${ }^{5}$ Department of Nutrition and Physiology, National Institute of Animal Science, RDA, JeonJu 55365, Korea \\ ${ }^{6}$ Graduate School of International Agricultural Technology, Pyeongchang Campus, Seoul National University, Pyeongchang 25354, Korea
}

\section{Abstract}

This study aimed to determine the effective dose of intravenous administration of L-tryptophan (L-T) on gastrointestinal hormones $(\mathrm{GIH})$ secretions and melatonin using Hanwoo cattle. Three steers $(362 \pm 23 \mathrm{~kg})$ fitted with indwelling jugular vein catheters were assigned in a $3 \times 3$ Latin square design. Treatments were intravenous administration of saline (control), 28.9 $\mathrm{mg} \mathrm{L-T/kg} \mathrm{body} \mathrm{weight} \mathrm{(BW;} \mathrm{low)} \mathrm{and} 57.8 \mathrm{mg} \mathrm{L-T/kg} \mathrm{BW} \mathrm{(high)} \mathrm{L-T} \mathrm{for} 1$ day with 7 days of adaptation. Samples were collected after adaptation period at $-60,0,30,60,90,120,150,180,240$, and $300 \mathrm{~min}$ of sampling day. The levels of serum cholecystokinin $(\mathrm{CCK})$ and secretin were higher $(p<0.05)$ in the high L-T group than those in the other groups. Serum Melatonin (MEL) levels were increased upon L-T administration $(p<0.05)$ in the high L-T group. Taken together, the effective dose of L-T administration was defined at $57.8 \mathrm{mg} \mathrm{L-T} / \mathrm{kg} \mathrm{BW}$ in order to stimulate increase of GIH and MEL.

Keywords: Amino acid, Cholecystokinin, Ghrelin, Melatonin, L-Tryptophan

\section{Background}

Gastrointestinal hormones (GIH) have putative roles on physiological and biological reactions, companion enzyme activity, nutrient digestion, and meat quality $[1,2]$, resulting in a higher level of humans' health as consumers of meat. Cholecystokinin (CCK), secretin, and ghrelin are well-known GIH involved in several enzymes interrelation activities [3], many digestive processes [4], and in mechanisms which lead to higher meat quality. However, an understanding of the roles of the aforementioned hormones without considering the other factors that affect beef quality, amino acids (AA) [1], and their effects on GIH changes is imperfect, and needs further clarification.

L-tryptophan (L-T) as an essential component of protein synthesis is involved in the formation of serotonin and melatonin (MEL) [2,5,6], which has been reported to modulate the structural and functional composition of the intestinal microbiome in broiler chicks [7] and weaned piglets [4,8]. It has also been demonstrated that administration of L-T stimulates an increase of MEL synthesis in mice [9]. Both L-T and MEL were closely re-

Received: Mar 29,2019 Revised: Jun 5, 2019 Accepted: Jun 10, 2019

"Corresponding author: Hong-Gu Lee, Department of Animal Science and Technology, College of Animal Bioscience and Technology, Konkuk University, Seoul 05029, Korea.

Tel: +82-2-450-0410, E-mail: hglee66@konkuk.ac.kr

This is an Open Access article distributed under the terms of the Creative Commons Attribution Non-Commercial License (http://creativecommons.org/licenses/bync/4.0/) which permits unrestricted non-commercial use, distribution, and reproduction in any medium, provided the original work is properly cited.

Copyright (C) 2019 Korean Society of Animal Science and Technology. 


\section{JAST}

lated to CCK, an endocrine hormone that can eventually improve feed digestion $[1,8]$. L-T deficiency may have a negative impact on food consumption and growth in monogastric animals $[1,10,11]$. In humans, it has been reported that intravenous administration of L-T increases prolactin and growth hormone in healthy subjects [12]. Additionally, an increase of MEL and ghrelin by L-T can stimulate the secretion of CCK $[9,13,14]$. Despite these important effects on GIH, the impact of L-T, which nutrients regulate GIH and MEL secretions, are largely unknown. Moreover, original research has been using laboratory animals such as mice to expand the knowledge in nutritional and hormonal aspects for the ease of experiment, lower costs, and higher growth and reproduction rates, etc. However, in the case of GIH research, extending the results obtained using laboratory animals to poly-gastric animals has been restricted due to natural differences and various reactions of $\mathrm{AA}$ supplementation by GIH tracts and stimulators in different species. A paucity of knowledge exists regarding the effects of intravenous administration of $\mathrm{L}-\mathrm{T}$ in poly-gastric animals particularly beef cattle. An investigation of this phenomenon has potential to provide insights into the hormonal consequences of L-T administration with various dosages. Therefore, in order to find out the effective dosage of L-T administration into the blood, this study was undertaken to determine if similar neuroendocrine effects to those elicited could be obtained by an intravenous administration of $\mathrm{L}-\mathrm{T}$ in beef cattle. The results of this work have potential to be used widely by the animal scientist community and particularly in ruminant studies.

\section{Materials and Methods}

\section{Animals and management system}

The experimental procedure and methods were approved by the Animal Welfare and Ethics Authority of Pusan National University, Myrang, Korea. Three Korean native steers [ave. body weight $(\mathrm{BW})=362 \pm 23 \mathrm{~kg}$ ], with catheters in their jugular veins, were used. Animal intravenous $14 \mathrm{G}$ catheters (large animal intravenous catheter, NIPRO, Osaka, Japan) were connected to three-way valves (3W-RC type, NIPRO, Osaka, Japan) and inserted into their jugular veins for the simultaneous administration of L-T and blood sampling. Animals were kept in individual cattle sheds with a fence of $4 \times 5 \mathrm{~m}$ and rice hulls on a concrete floor. Water was provided ad libitum. Each route in the cattle shed was closed 1 day prior to the experiment to block out light, thus minimizing its effect on MEL secretion. The cattle were fed according to their daily nutrient requirements and daily gain based on the NIAS standard [15]. Basal feed included timothy hay and concentrated feed (Table 1) to meet the daily energy consumption requirements for Korean native steers [15] and was provided twice daily at 800 and 1,700 h. Proximal analyses were performed based on AOAC [16]. Tryptophan in the feed and its requirement is not given due to the limitations in assay procedure as the similar limitation analysis has been stated by the Nutrient Requirements of Beef Cattle [17].

\section{Treatment preparation}

The powder form of 100\% L-T (Sigma Co, St. Louis, MO, USA; Assay Spec. $\geq 98 \%$ by TLC) was used. The powder was dissolved in sterile saline and injected into jugular vein according to the method described by Kasuya et al. [3]. The total amount of L-T administered was set as low L-T (i.e. $28.9 \mathrm{mg} / \mathrm{kg}$ BW) or high L-T (i.e. $57.8 \mathrm{mg} / \mathrm{kg}$ BW). Sterile saline $(1 \mathrm{~L})$ was used as a control. Completely dissolved solution was filtered to remove external pollutants during degradation. All equipment used to prepare L-T solution was sterilized before use.

\section{Experimentation design and treatment}

Steers were freely assigned into a $3 \times 3$ Latin square design including the following treatments: i) control (basal diet + physiological saline); ii) low L-T (basal diet + $28.9 \mathrm{mg} \mathrm{L}-\mathrm{T} / \mathrm{kg} \mathrm{BW}$ ); iii) high L-T (basal diet $+57.8 \mathrm{mg} \mathrm{L-T} / \mathrm{kg}$ BW). After an adaptation period ( 7 days), treatments were administered via the jugular vein using a peristaltic pump for a period of $2 \mathrm{~h}(1,200$ to $1,400 \mathrm{~h})$. The treatment dosage was determined based on individual body weight measured one day prior to the study.

\section{Serum sampling}

Blood was obtained from the jugular vein at $60 \mathrm{~min}(1,100 \mathrm{~h})$ before L-T administration, $0 \mathrm{~min}(1,200 \mathrm{~h})$ before administration, and $30 \mathrm{~min}(1,230 \mathrm{~h}), 60 \mathrm{~min}(1,300 \mathrm{~h}), 90 \mathrm{~min}$ (1,330 h), $120 \mathrm{~min}$ (1,400 h), $150 \mathrm{~min}$ (1,430 h), $180 \mathrm{~min}$ (1,500 h), $240 \mathrm{~min}$ (1,600 h), and $300 \mathrm{~min}(1,700 \mathrm{~h})$ after AA administration. Blood was moved

Table 1. Proximate analyses ${ }^{1)}$ of basal diets in Korean native steers administered different doses of L-tryptophan intravenous or saline

\begin{tabular}{lccccc}
\hline & Water (\%) & \multicolumn{4}{c}{$\%$ of dry matter } \\
\cline { 3 - 6 } & & Crude protein & Ether extract & Crude ash & TDN \\
\hline Timothy & $7.99 \pm 0.01$ & $6.72 \pm 0.02$ & $1.09 \pm 0.01$ & $6.62 \pm 0.02$ & $66.66 \pm 0.13$ \\
Concentrate & $13.28 \pm 0.06$ & $12.47 \pm 0.04$ & $3.00 \pm 0.02$ & $7.19 \pm 0.04$ & $69.50 \pm 0.20$ \\
\hline
\end{tabular}

${ }^{11}$ Calculated values in the laboratory.

TDN, total digestible nutrients. 
to the serum tube (BD Vacutainer, BD, USA) for storage at $4{ }^{\circ} \mathrm{C}$ immediately after sampling. Samples were centrifuged $(2,000 \times \mathrm{g}$, $15 \mathrm{~min}$ ) to separate serum. The supernatant was added to a $1.5 \mathrm{ml}$ tube and stored at $-80^{\circ} \mathrm{C}$ before analysis.

Immunoassay for establishing and analyzing GIH (ghrelin, secretin, and CCK-8) and MEL in bovine

Serum concentrations of ghrelin, secretin, and CCK-8 were measured by enzyme immunoassay using secondary antibodies for ghrelin (EK-031-30), secretin (EK-067-05), and CCK-8 (EK069-04) (Phoenix Pharmaceuticals, USA) with a human melatonin ELISA Kit (RE54021) (IBL, Germany). Serum was prepared for analyses and to test the cross reactivity of standards in the kit using the method described by Lee et al. [2].

\section{Statistical analysis}

Data of serum MEL and GIH were analyzed using one-way analysis of variance (AVOVA). All statistical analyses were performed using SPSS software package (SPSS, Chicago, IL, USA). Statistical significance was considered when the $p$-value was less than 0.05 or 0.01 .

\section{Results}

\section{Response of MEL following L-T administration}

In this study, intravenous administration of $28.9 \mathrm{mg} / \mathrm{kg}$ BW of L-T was increased $(p<0.05)$ MEL after 30 min compared to the control (Fig. 1). However, no significant difference $(p>0.05)$ was observed over the total period (average of total period) during the administration and up to $5 \mathrm{~h}$ after injection (Table 2). Intravenous-

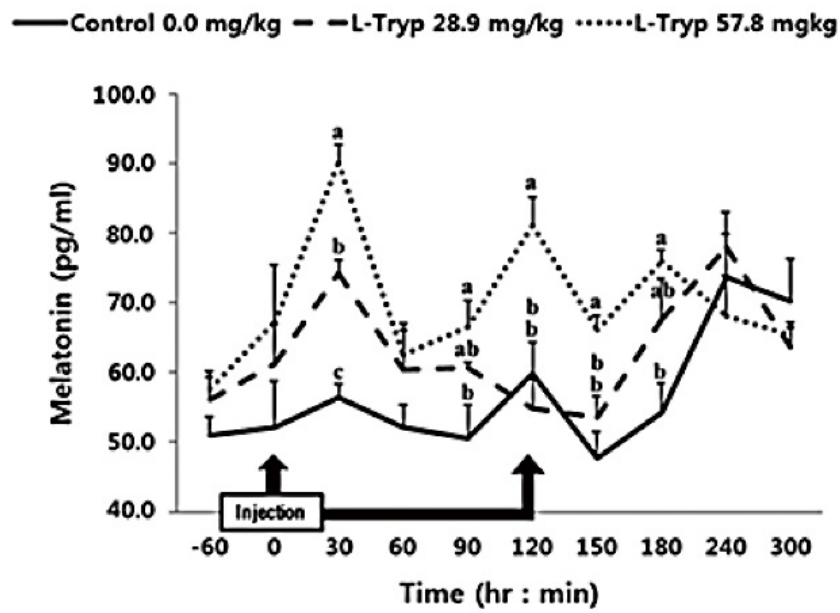

Fig. 1. Changes in the levels of serum melatonin following intravenous administration of L-tryptophan in Hanwoo steers. ${ }^{a-c} p<0.05$.

Table 2. Effects of intravenous administration of L-tryptophan on serum melatonin and gastrointestinal hormones concentrations in Hanwoo steers

\begin{tabular}{|c|c|c|c|c|}
\hline & & \multirow{2}{*}{ Control } & \multicolumn{2}{|c|}{ L-tryptophan } \\
\hline & & & $28.9 \mathrm{mg} / \mathrm{kg}$ & $57.8 \mathrm{mg} / \mathrm{kg}$ \\
\hline \multirow[t]{4}{*}{ Melatonin (pg/mL) } & Before $^{1)}$ & $51.70 \pm 4.970$ & $58.85 \pm 4.455$ & $64.30 \pm 5.185$ \\
\hline & After ${ }^{2)}$ & $58.25 \pm 2.985^{b}$ & $64.25 \pm 3.125^{\mathrm{ab}}$ & $72.10 \pm 3.020^{a}$ \\
\hline & Mean $^{3)}$ & $56.95 \pm 2.595^{\mathrm{b}}$ & $63.15 \pm 2.650^{\mathrm{ab}}$ & $70.55 \pm 2.655^{\mathrm{a}}$ \\
\hline & Increment $t^{4)}$ & $6.55 \pm 2.985$ & $5.40 \pm 3.125$ & $7.80 \pm 3.020$ \\
\hline \multirow[t]{4}{*}{ Cholecystokinin (ng/mL) } & Before & $7.09 \pm 0.419$ & $8.11 \pm 0.684$ & $9.73 \pm 2.164$ \\
\hline & After & $8.06 \pm 1.012^{b}$ & $10.39 \pm 0.712^{b}$ & $17.24 \pm 2.416^{\mathrm{a}}$ \\
\hline & Mean & $7.86 \pm 0.813^{b}$ & $9.93 \pm 0.605^{b}$ & $15.74 \pm 2.044^{\mathrm{a}}$ \\
\hline & Increment & $0.97 \pm 1.012^{b}$ & $2.28 \pm 0.712^{b}$ & $7.52 \pm 2.416^{a}$ \\
\hline \multirow[t]{4}{*}{ Secretin (ng/mL) } & Before & $7.93 \pm 2.542$ & $7.93 \pm 2.606$ & $7.94 \pm 2.565$ \\
\hline & After & $7.52 \pm 1.268^{b}$ & $9.78 \pm 0.924^{b}$ & $15.02 \pm 2.790^{a}$ \\
\hline & Mean & $7.60 \pm 1.116^{b}$ & $9.41 \pm 0.892^{\mathrm{ab}}$ & $13.60 \pm 2.333^{\mathrm{a}}$ \\
\hline & Increment & $-0.41 \pm 1.268^{b}$ & $1.85 \pm 0.924^{\mathrm{b}}$ & $7.08 \pm 2.790^{\mathrm{a}}$ \\
\hline \multirow[t]{4}{*}{ Ghrelin (ng/mL) } & Before & $16.19 \pm 1.987$ & $14.65 \pm 4.500$ & $21.45 \pm 3.452$ \\
\hline & After & $19.99 \pm 1.419$ & $15.88 \pm 1.814$ & $17.90 \pm 1.366$ \\
\hline & Mean & $19.23 \pm 1.222$ & $15.63 \pm 1.672$ & $18.61 \pm 1.290$ \\
\hline & Increment & $3.80 \pm 1.419^{a}$ & $1.23 \pm 1.814^{\mathrm{a}}$ & $-3.55 \pm 1.366^{b}$ \\
\hline
\end{tabular}

\footnotetext{
${ }^{1)}$ Before, average -60 to zero min before jugular vein injection of L-tryptophan

${ }^{2)}$ After, average zero to $300 \mathrm{~min}$ after jugular vein injection of L-tryptophan.

${ }^{3)}$ Total, average -60 to 300 min during jugular vein injection of L-tryptophan.

${ }^{4)}$ Increment, after and before.

${ }^{\mathrm{a}-c}$ in rows $p<0.05$
} 
ly administration of $57.8 \mathrm{mg} / \mathrm{kg}$ BW of L-T significantly increased $(p<0.05)$ MEL synthesis at 30 and 120 min post administration. MEL synthesis was also significantly increased $(p<0.05)$ both during and post L-T administration compared to that in the control group.

\section{Responses of GIH secretions following L-T administration} There was no increase $(p>0.05)$ in serum concentrations of CCK (Fig. 2) and secretin (Fig. 3) in the low L-T group. However, there was a significant increase $(p<0.05)$ in CCK and secretin in the high L-T group (Table 2).

The concentration of serum ghrelin in the low and high L-T groups showed a downward compared to that of the control group (Fig. 4). A dose-dependent decrease in serum ghrelin was found

\section{—Control $0.0 \mathrm{mg} / \mathrm{kg}$ - -L-Tryp $28.9 \mathrm{mg} / \mathrm{kg} \cdots \cdot$. L-Tryp $57.8 \mathrm{mgkg}$}

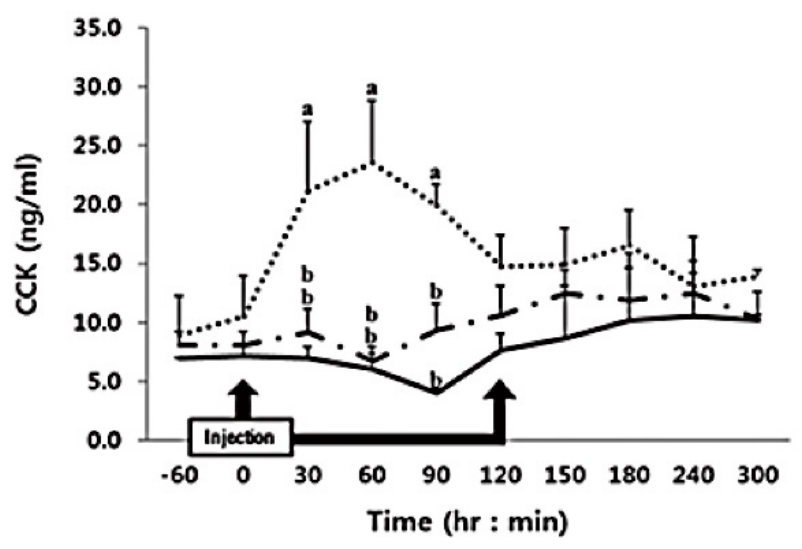

Fig. 2. Changes in the levels of serum cholecystokinin following intravenous administration of L-tryptophan in Hanwoo steers. ${ }^{a-c} p<$ 0.05 .

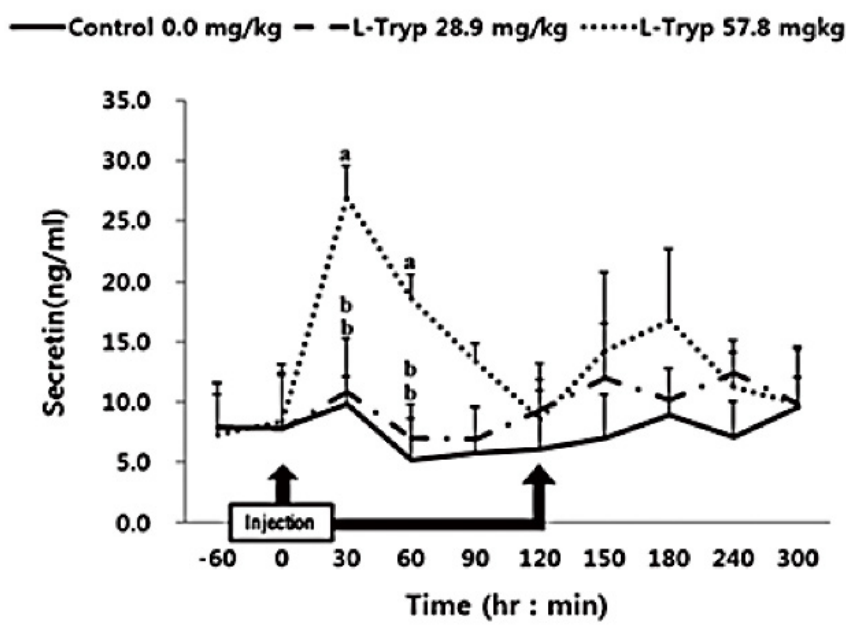

Fig. 3. Changes in the levels of serum secretin following intravenous administration of L-tryptophan in Hanwoo steers. ${ }^{a-c} p<0.05$.

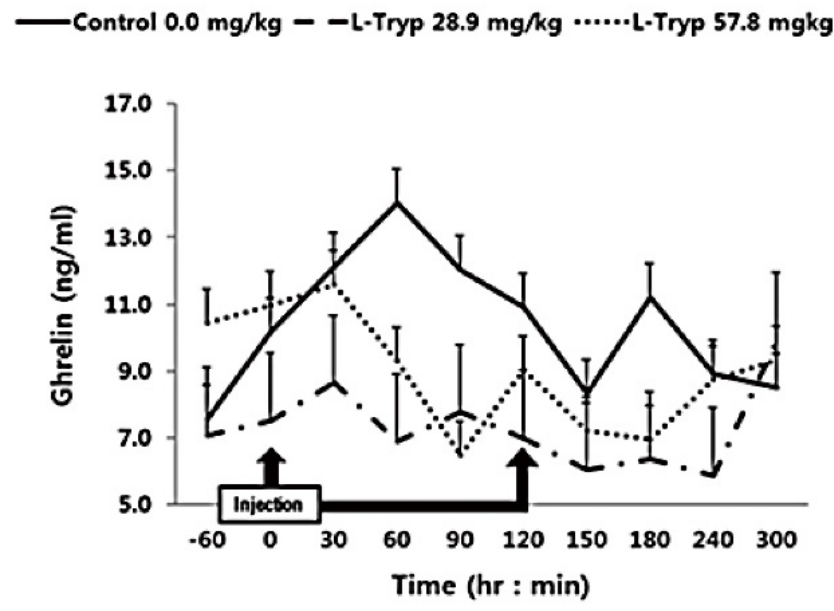

Fig. 4. Changes in the levels of serum ghrelin following intravenous administration of L-tryptophan in Hanwoo steers. ${ }^{a-c} p<0.05$.

following L-T administration, when samples were taken before and after administration. A significant decrease $(p<0.05)$ in serum ghrelin concentration was found in the high L-T group compared to the control group (Table 2).

\section{Discussion}

Administration of L-T for both 28.9 and $57.8 \mathrm{mg} / \mathrm{kg}$ BW resulted in a dose-dependent increase in serum MEL concentration (Fig. 1 and Table 2). Jaworek et al. [16] reported that infusion of L-T (50 and $250 \mathrm{mg} / \mathrm{kg}$ BW) into the peritoneum or duodenum in mice increased the activity of plasma MEL. Administration of L-T for $28.9 \mathrm{mg} / \mathrm{kg}$ BW, caused an upward in serum concentration of GIHs including CCK and secretin compared to the control (Fig. 1 and Table 2). However, a dose-dependent increase in the treatment group was observed in response to the high L-T administration. Our finding complies with the findings by Leja-Szpak et al. [9] in mice, who reported an increase in serum MEL followed by administration of L-T. L-T and MEL have shown a positive relationship with CCK [4], which can ultimately increase the synthesis of pancreatic $\alpha$-amylase to help digestion. Ghrelin, MEL, tryptophan, and other hormones can stimulate increasing CCK levels and the secretion of starch-degrading enzymes in monogastric $[8,13]$. The same phenomenon was approved in Hanwoo cattle in the present study. Therefore, increased MEL synthesis following L-T treatment might have increased the secretion of intestinal hormones including CCK.

Serum concentration of ghrelin was significantly decreased in the group administered with high L-T compared to the control in agreement with the study by Zhang et al. [17] in weaned pigs who reported higher plasma ghrelin in response to dietary supplemen- 
tation of L-T [1]. Furthermore, L-T supplementation stimulated an increase in secretion of serotonin in the central nervous system [18-19]. Kasuya et al. [3] reported that L-T could stimulate 5-hydroxytryptamine (serotonin) secretion. However, treatment of the hypothalamic nervous structure of mice with ghrelin inhibited the secretion of 5-hydroxytryptamine [20]. To date, mechanisms behind modulation of blood ghrelin by L-T remained unclear. In general, the secretion of CCK is stimulated by the degradation of chain peptides and small molecules that enter the duodenum [21] and thus affect the meat production and quality. Secretion of CCK is related to the uptake of chained AA [22]. Furthermore, induction of endogenous MEL by L-T strongly stimulates the secretion of pancreatic proteins $[9,16]$. Leja-Szpak et al. [9] reported that administration of the L-T to mice can affect the synthesis of the pineal hormone MEL. Therefore, since both L-T and MEL are closely associated to the intestinal hormone $\mathrm{CCK}$, the production of pancreatic $\alpha$-amylase can be increased and thus be a theme of future in-vivo studies.

This study improved our understanding of how GIHs increase due to L-T administration as a source of AA. The results have a potential to be a theme of future ruminant studies aiming at maximizing of meat quality by dietary implication of L-T to safely passing from the rumen (encapsulating L-T). Collectively, this study endorsed the previous findings in laboratory and or monogastric animals with poly-gastric animals by which the effective dose of L-T found to be $57.8 \mathrm{mg} \mathrm{L}-\mathrm{T} / \mathrm{kg}$ BW, when administered intravenously. However, the oral rate of L-T, in practice, to achieve the same effective dose, need further research. Given the absorption rate of L-T via GIT ( 72\%), future studies can be designed to employ encapsulated L-T for oral use to investigate if similar results could be attained.

\section{Competing interests}

The authors declare no conflict of interest.

\section{Funding sources}

Not applicable.

\section{Acknowledgements}

This work was supported by Cooperation Research Project (2017R1A2B2009752) funded by the National Research Foundation of Korea.

\section{Availability of data and material}

Please contact author for data requests.

\section{Authors' contributions}

Conceptualization and hypothesis: Lee SB, Lee HG.
Data curation: Lee SB, Lee KW, Wang T.

Statistical analysis: Lee JS, Jung US.

Methodology and laboratory analyses: Lee SB, Lee KW, Lee JS, Jung US.

Writing first draft: Lee SB, Lee KW, Lee JS.

Writing, reviewing and editing: Ghassemi Nejad J.

Preparation, experiments, and discussion: Oh YK, Baek YC, Kim KH.

Supervised the experiment, supporting the experiment financially: Lee HG.

\section{Ethics approval and consent to participate}

This article does not contain any studies with human subjects performed by any of the authors. The experimental procedure and methods were approved by the Animal Welfare and Ethics Authority of Kangwon National University, Chuncheon, Korea.

\section{ORCID}

Sang-Bum Lee https://orcid.org/0000-0001-5761-8483 Kyung-Won Lee Tao Wang Jae-Sung Lee U-Suk Jung Jalil Ghassemi Nejad Young-Kyoon $\mathrm{Oh}$ Youl-Chang Baek Kyoung Hoon Kim Hong-Gu Lee https://orcid.org/0000-0001-8019-1860 https://orcid.org/0000-0002-1876-0097 https://orcid.org/0000-0001-8940-9862 https://orcid.org/0000-0003-4125-6179 https://orcid.org/0000-0001-6578-8829 https://orcid.org/0000-0002-5817-1748 https://orcid.org/0000-0003-4454-5339 https://orcid.org/0000-0002-7288-7443 https://orcid.org/0000-0002-0679-5663

\section{References}

1. Guzik AC, Matthews JO, Kerr BJ, Bidner TD, Southern LL. Dietary tryptophan effects on plasma and salivary cortisol and meat quality in pigs. J Anim Sci. 2006;84:2251-9.

2. Lee $\mathrm{SB}$, Choi CW, Jin YC, Wang T, Lee KH, Ku MB, et al. Effect of oral administration of intact casein on gastrointestinal hormone secretion and pancreatic alpha-amylase activity in Korean Native Steer. Asian-Australas J Anim Sci. 2013;26:654-60.

3. Kasuya E, Yayou K, Hashizume T, Kitagawa S, Sutoh M. A possible role of central serotonin in L-tryptophan-induced GH secretion in cattle. Anim Sci J. 2010;81:345-51.

4. Seeve B. Physiological roles of tryptophan in pig nutrition. In: Huether G, Kochen W, Simat TJ, Steinhart H, editors. Tryptophan, serotonin, and melatonin: basic aspects and applications. New York, NY, USA: Academic/Plenum; 1999. p.72941.

5. Ma H, Cheng J, Zhu X, Jia Z. Effects of rumen-protected tryptophan on performance, nutrient utilization and plasma 
tryptophan in cashmere goats. Afr J Biotechnol. 2011;10:580611.

6. Alkozi HA, Sanchez Montero JM, Doadrio AL, Pintor J. Docking studies for melatonin receptors. Expert Optin Drug Discov. 2018;13:241-8.

7. Bello AU, Idrus Z, Meng GY, Award EA, Farjam AS. Gut microbiota and transportation stress response affected by tryptophan supplementation in broiler chickens. Ital J Anim Sci. 2018;17:107-13.

8. Liang H, Dai Z, Liu N, Ji Y, Chen J, Zhang Y, et al. Dietary L-tryptophan modulates the structural and functional composition of the intestinal microbiome in weaned piglets. Front Microbiol. 2018;9:1-12.

9. Leja-Szpak A, Jaworek J, Nawrot-Porabka K, Palonek M, Mitis-Musiol M, Dembinski A, et al. Modulation of pancreatic enzyme secretion by melatonin and its precursor; L-tryptophan. Role of CCK and afferent nerves. J Physiol Pharmacol. 2004;55 Suppl 2:33-46.

10. Montgomery GW, Flux DS, Greenway RM. Tryptophan deficiency in pigs: changes in food intake and plasma levels of glucose, amino acids, insulin and growth hormone. Horm Metab Res. 1980;12:304-9.

11. Henry Y, Seve B, Colleaux Y, Ganier P, Saligaut C, Jego P. Interactive effects of dietary levels of tryptophan and protein on voluntary feed intake and growth performance in pigs, in relation to plasma free amino acids and hypothalamic serotonin.J Anim Sci. 1992;70:1873-87.

12. Charney DS, Heninger GR, Reinhard JF Jr, Strenberg DE, Hafstead KM. The effect of intravenous L-tryptophan on prolactin and growth hormone and mood in healthy subjects. Psychopharmacol. 1982;77:217-22.

13. Jaworek J. Ghrelin and melatonin in the regulation of pancreatic exocrine secretion and maintaining of integrity. J Physiol Pharmacol. 2006;57 Suppl 5:83-96.

14. Lee KH, Wang T, JinYC, Lee SB, Oh JJ, Hwang JH, et al. Identification of proteins involved in the pancreatic exocrine by exogenous ghrelin administration in Sprague-Dawley rats.J
Anim Sci Technol. 2014;56:6.

15. National Institute of Animal Science [NIAS]. Korean feeding standard for Hanwoo. Suwon, Korea: Rural Development Administration; 2007. p.158.

16. Association of Official Analytical Chemists [AOAC]. Official methods of analysis of AOAC. 13th ed. Washington, DC, USA: AOAC; 1980.

17. National Academies of Sciences, Engineering, and Medicine. Nutrient requiremnets of beef cattle. 8th ed. Washington, DC, USA: The National Academies Press; 2016. p.406.

18. Jaworek J, Nawrot K, Konturek SJ, Leja-Szpak A, Thor P, Pawlik WW. Melatonin and its precursor, L-tryptophan: influence on pancreatic amylase secretion in vivo and in vitro. J Pineal Res. 2004;36:155-64.

19. Zhang H, Yin J, Li D, Zhou X, Li X. Tryptophan enhances ghrelin expression and secretion associated with increased food intake and weight gain in weanling pigs. Domest Anim Endocrinol. 2007;33:47-61.

20. Arnold MA, Fernstrom JD. L-Tryptophan injection enhances pulsatile growth hormone secretion in the rat. Endocrinol. 1981;108:331-5.

21. Brunetti L, Recinella L, Orlando G, Michelotto B, Di Nisio C, Vacca M. Effects of ghrelin and amylin on dopamine, norepinephrine and serotonin release in the hypothalamus. Eur J Pharmacol. 2002;454:189-92.

22. Ipharraguerre IR, Clark JH. Impacts of the source and amount of crude protein on the intestinal supply of nitrogen fractions and performance of dairy cows. J Dairy Sci. 2005;88 Suppl 1:E22-37.

23. Go VL, Hofmann AF, Summerskill WH. Pancreozymin bioassay in man based on pancreatic enzyme secretion: potency of specific amino acids and other digestive products.J Clin Invest. 1970;49:1558-64.

24. Hashimoto N, Hara H. Dietary branched-chain amino acids suppress the expression of pancreatic amylase mRNA in rats. Biosci Biotechnol Biochem. 2004;68:1067-72. 